\title{
GENDER COMMONALITIES AND DIFFERENCES IN RISK AND PROTECTIVE FACTORS OF SUICIDAL THOUGHTS AND BEHAVIORS: A CROSS-SECTIONAL STUDY OF SPANISH UNIVERSITY STUDENTS
}

\section{Gender and suicidal ideation in Spanish university students}

Andrea Miranda-Mendizabal ${ }^{1,2}$, Pere Castellvî́, Itxaso Alayo ${ }^{1,4}$, Gemma Vilagut ${ }^{1,4}$, Maria Jesús Blasco ${ }^{1,4}$, Aina Torrent ${ }^{5}$, Laura Ballester ${ }^{1,4,6}$, José Almenara ${ }^{7}$, Carolina Lagares ${ }^{7}$, Miquel Roca ${ }^{8}$, Albert Sesé ${ }^{8}$, José Antonio Piqueras ${ }^{9}$, Victoria Soto-Sanz ${ }^{9}$, Jesús Rodríguez-Marín ${ }^{9}$, Enrique Echeburúa ${ }^{10}$, Andrea Gabilondo $^{11}$, Ana Isabel Cebrià ${ }^{12}$, Ronny Bruffaerts ${ }^{13}$, Randy P. Auerbach ${ }^{14,15}$, Philippe Mortier ${ }^{1}$, Ronald C. Kessler ${ }^{16}$, Jordi Alonso ${ }^{1,2,4}$ on behalf of the UNIVERSAL study group.

1 Health Services Research Group, IMIM-Institut Hospital del Mar d'Investigacions Mèdiques, Barcelona, Spain

2 Department of Health \& Experimental Sciences, Pompeu Fabra University (UPF), Barcelona, Spain

3 Department of Psychology, University of Jaén, Jaén, Spain.

4 CIBER Epidemiología y Salud Pública (CIBERESP), Madrid, Spain.

5 Health and Life Sciences Faculty, Pompeu Fabra University (UPF), Barcelona, Spain

6 Girona University (UdG), Girona, Spain

7 University of Cadiz (UCA), Cádiz, Spain.

8 Institut Universitari d'Investigació en Ciències de la Salut (IUNICS-IDISPA), University of Balearic Islands (UIB), Palma de Mallorca, Spain.

9 Miguel Hernandez University of Elche (UMH), Alicante, Spain.

10 University of the Basque Country (UPV-EHU), Bilbao, Spain.

11 Outpatient Mental Health Care Network, Osakidetza-Basque Health Service. Biodonosti Health Research Institute, San Sebastian, Spain.

12 Department of Mental Health, Corporació Sanitaria Parc Taulí, Sabadell, Spain.

13 Universitair Psychiatrisch Centrum, KU Leuven (UPC-KUL), Leuven, Belgium.

14 Department of Psychiatry, Harvard Medical School, Boston, MA, USA. 
15 Center for Depression, Anxiety and Stress Research, McLean Hospital, Belmont, MA, USA.

16 Department of Health Care Policy, Harvard Medical School, Boston, MA, USA.

Corresponding author: Dr. Jordi Alonso. IMIM-Institut Hospital del Mar d’Investigacions Mèdiques, PRBB Building. Doctor Aiguader 88. 08003 Barcelona, Spain.

Phone number: 00349331607 60; Fax: 0034933160797.

E-mail: jalonso@imim.es.

Conflict of interest: Dr. Kessler has received support for his epidemiological studies from Sanofi Aventis; has served as a consultant for Johnson and Johnson Wellness and Prevention, Shire, Takeda; and has served on an advisory board for the Johnson and Johnson Services, Inc. Lake Nona Life Project, in the past 3 years. He is a co-owner of DataStat, Inc., a market research firm that carries out healthcare research.

\section{Funding}

This work was supported by Fondo de Investigación Sanitaria, Instituto de Salud Carlos III-FEDER (PI13/00343); Ministerio de Sanidad, Servicios Sociales e Igualdad, PNSD (Exp. 2015I015); ISCIII (Río Hortega, CM14/00125); ISCIII (Sara Borrell, CD12/00440; CD18/00049); Ministerio de Educación, Cultura y Deporte (FPU15/05728); Generalitat de Catalunya (2017 SGR 452). 


\section{ABSTRACT}

Aim

To assess gender-differences in the association between risk/protective factors and suicidal thoughts and behaviors (STB); and whether there is any gender-interaction with those factors and STB; among Spanish university students.

\section{Methods}

Data from baseline online survey of UNIVERSAL project, a multicenter, observational study of first-year Spanish university students (18-24 years). We assessed STB; lifetime and 12-month negative life-events and family adversities; mental disorders; personal and community factors. Gender-specific regression models and gender-interactions were also analyzed.

\section{Results}

We included 2,105 students, 55.4\% women. Twelve-month prevalence of suicidal ideation (SI) was $10 \%$, plans $5.7 \%$, attempts $0.6 \%$. Statistically significant gender-interactions were found for lifetime anxiety disorder, hopelessness, violence between parents, chronic health conditions and family support. Lifetime mood disorder was a common risk factor of SI for both genders (Females: OR=5.5; 95\%CI 3.3-9.3; Males: $\mathrm{OR}=4.4 ; 95 \% \mathrm{CI} 2.0-9.7)$. For females, exposure to violence between parents $(\mathrm{OR}=3.5 ; 95 \% \mathrm{CI}$ 1.7-7.2), anxiety disorder (OR=2.7; 95\%CI 1.6-4.6), and alcohol/substance disorder (OR=2.1; 95\%CI 1.14.3); and for males, physical childhood maltreatment ( $\mathrm{OR}=3.6$; 95\% CI 1.4-9.2), deceased parents $(\mathrm{OR}=4.6 ; 95 \% \mathrm{CI}$ 1.2-17.7), and hopelessness $(\mathrm{OR}=7.7 ; 95 \% \mathrm{CI} 2.8-21.2)$, increased SI risk. Family support $(\mathrm{OR}=0.5 ; 95 \% \mathrm{CI} 0.2-0.9)$ and peers/others support $(\mathrm{OR}=0.4 ; 95 \% \mathrm{CI} 0.2-0.8)$ were associated to a lower SI risk only among females.

\section{Conclusions}

Only mood disorder was a common risk factor of SI for both genders, while important gender-differences were observed regarding the other factors assessed. Protective effect from family and peers/others support was observed only among females. Further research assessing underlying mechanisms and pathways of gender-differences is needed.

Keywords: gender, suicide/self-harm, mood disorders, anxiety/anxiety disorders, depression. 


\section{INTRODUCTION}

Suicide is the second leading cause of death among 15- to 29-year-olds (World Health Organization, 2016). In Spain in 2015, suicide was the first cause of death among 15- to 19-year-old women and the second among 20- to 24-year-old men (Instituto Nacional de Estadísticas, 2015). More current data shows that suicide rates among 15 - to 29 -year-olds represent a $7.77 \%$ of the total suicide deaths in the country (Navarro-Gómez, 2017).

Prevalence estimates of suicidal thoughts and behaviors (STB) among university students are consistently high. Before ending university, over one-tenth of the students would seriously consider suicide and onesixth would attempt suicide (Ashrafioun, Bonar, \& Conner, 2016). Results from 19 universities from eight countries showed $17.2 \%, 8.8 \%$, and 1.0\% 12-month prevalence of suicidal ideation (SI), plans and attempts, respectively (Mortier et al., 2018). From those, Northern Ireland results raise attention: almost the double individuals ( $31 \%$ total; $24.3 \%$ males, $36.9 \%$ females) reported 12 -month SI, with almost 1 in 5 students having made a suicide plan (O’Neill et al., 2018).

Mental disorders are highly prevalent among university students (Auerbach et al., 2016; Eskin et al., 2016; Pedrelli, Nyer, Yeung, Zulauf, \& Wilens, 2015). Mood, anxiety, disruptive, alcohol/substance abuse disorders increase STB more frequently (Cash \& Bridge, 2009; Mortier et al., 2018). Mental disorders also increase distress (Eskin et al., 2016) and substantial impairment in academic performance (Auerbach et al., 2016). Childhood and adolescent adversities, bullying, stressful life experiences and personal traits could also be related (Holt et al., 2015; Johnson et al., 2002; L. Wang et al., 2014; Werbart Törnblom, Werbart, \& Rydelius, 2015). On the contrary, positive relationships with peers and family might be STB protective factors (Cash \& Bridge, 2009; Thompson, Eggert, \& Herting, 2000).

A "gender paradox" exists regarding suicidal behavior. Males have higher rates of completed suicide and lower rates of suicide attempt, compared to females. Likewise, males are three- to four-fold more likely to die by suicide than females (Eaton, Kann, \& Jinchen, 2012; Werbart Törnblom et al., 2015). The association between suicide and masculinity may play a role in creating a genuine gender gap in suicide rates (Canetto \& Sakinofsky, 1998). Males are more likely to resort to more lethal means in order to reduce the likelihood of surviving (Mergl et al., 2015; Värnik et al., 2008). Gender-differences between 
internalizing (e.g. mood disorders) and externalizing (e.g. conduct disorders) disorders may also be related (Boyd et al., 2015). The few empirical data available about gender paradox in Spain suggest similar gender trends for STB (Navarro-Gómez, 2017).

Most of the evidence about STB risk and protective factors come from Anglo-Saxon countries; Spanish cross-national data is limited. Moreover, available evidence of gender-differences in STB risk and protective factors is not specific for university students (Miranda-Mendizabal et al., 2019). This study aims to determine the association between risk and protective factors and STB stratified by gender, and to assess whether there is any interaction between those factors and gender with STB among Spanish university students. Results from the present study will advance the understanding of the epidemiological gender-differences of STB among university students.

\section{METHODS}

\section{Study design and setting}

Data came from baseline survey (October 2014 to October 2015) of the UNIVERSAL (University and Mental Health) project, an ongoing, multicenter and observational study of first-year Spanish university students. This project is part of the World Mental Health International College Student Initiative (WMHICS) (http://www.hcp.med.harvard.edu/wmh/college_student_survey.php). More project details can be found elsewhere (Blasco et al., 2016).

Sample was recruited from five Spanish public universities: Cadiz University (UCA), Balearic Islands University (UIB), Basque Country University (UPV-EHU), Pompeu Fabra University (UPF) and Miguel Hernández University (UMH), representing about $8 \%$ of the undergraduate enrolment capacity annually offered in the country. Inclusion criteria were: a) students aged 18 to 24 (subjects under 18 at the start of the academic year were eligible when they turned 18); and b) being enrolled in the first university year for the first time. Students not accepting the study's informed consent were excluded. Based on eligibility criteria, 16,332 students were suitable to participate (Figure 1). Participants underwent an online survey via a secure web-based platform designed for the study. 
Sample recruitment was performed in two stages. First, all first-year undergraduates were invited to participate in baseline survey (e.g., census sampling). Invitation methods across the universities included: campus advertising campaigns (e.g., information stands, university website) and up to four personal email invitation letters from the university authorities. Second, a random subsample of non-respondents to the first stage was contacted by e-mail including an economic incentive of $25 €$ to complete the survey (“endgame strategy"). In UPV-EHU, only stage one was carried out. Protocol of the study was approved by Parc de Salut MAR-Clinical Research Ethics Committee (Reference number 2013/525/I).

\section{Variables}

$\underline{\text { Suicidal thoughts and behaviors (STB) }}$

STB were assessed through ideation ("Have you ever had thoughts of killing yourself?"); possibly accompanied by plans ("Did you ever think about how you might kill yourself or work out a plan of how to kill yourself?") or attempts ("Did you ever have a suicide attempt (i.e., purposefully hurt yourself with at least some intent to die)?"); from modified versions of the Self-Injurious Thoughts and Behaviors Interview (SITBI) (Nock, Holmberg, Photos, \& Michel, 2007) and Columbia-Suicide Severity Rating Scale (C-SSRS) (Posner, Oquendo, Gould, Stanley, \& Davies, 2007).

\section{Negative life events and family adversity}

Childhood maltreatment items, prior to the age of 17, included emotional maltreatment (e.g. "Someone in your family repeatedly said hurtful or insulting things to you"), physical abuse (e.g. "Someone in your family hit you so hard that it left bruises or marks"), sexual abuse ("Someone in your family touched you or made you touch them in a sexual way against your will"), and neglect (e.g. "You were seriously neglected at home”). Four items assessed physical, verbal and cyberbullying victimization: “How often were you bullied at school: physically/verbally by someone who purposefully ignored you, excluded you, or spread rumors about you behind your back?" and "How often were you bullied over internet or by text messaging?" Dating violence was evaluated with "How often were you in a romantic relationship where your partner repeatedly hit you/said hurtful or insulting things to you?" Family adversity included deceased parents, parental separation or divorce, psychopathology or criminal activities, any parent attempted or died by suicide, and violence between parents. Items were adapted from the CIDI 3.0 
(Kessler \& Ustün, 2004), the Adverse Childhood Experiences Scale (CES) (Felitti et al., 1998) and the Bully Survey (BS) (Swearer \& Cary, 2003).

\section{Stressful events experienced in the past 12 months}

These included death of a friend/family member, life-threatening illness or injury of a friend/family member, stressors related to a romantic partner (breakup or cheating), betrayal, arguments or breakup with friends/family member, interpersonal conflicts (fights with romantic partner/family member/someone else you know/stranger), life-threatening accidents, serious physical assault, sexual assault or rape, trouble with police or serious legal problems and others stressful experiences. Items were adapted from the Life Events Questionnaire (Brugha \& Cragg, 1990), the Deployment Risk and Resilience Inventory Survey (Vogt, Proctor, King, King, \& Vasterling, 2008) and the Department of Defense Survey of Health-Related Behaviors among active duty military personnel (Bray et al., 2009).

\section{$\underline{\text { Individual factors }}$}

Probable lifetime mood disorder (major depressive or bipolar disorder) and anxiety disorder (panic or generalized anxiety disorder) were evaluated using CIDI 3.0 (Kessler \& Ustün, 2004) and Epi-Q Screening Survey (EPIQ-SS) (Kessler et al., 2010). Probable lifetime alcohol or substance disorder (abuse or dependence) was screened through a modified version of the Alcohol Use Disorders Identification Test, 10-item version (AUDIT-10) (Saunders, Aasland, Babor, de la Fuente, \& Grant, 1993) and items from the CIDI 3.0 (Kessler \& Ustün, 2004). Hopelessness was evaluated with selected items from Beck Hopelessness Scale (BHS) (Beck, Weissman, Lester, \& Trexler, 1974). Students were asked whether they had epilepsy, seizure disorder or any chronic condition (e.g. asthma, diabetes, migraine). Physical impairment (e.g., vision, hearing, movement) was also assessed.

\section{$\underline{\text { Community factors }}$}

Access to means was assessed with "In the past 12 months, how many times did you carry a weapon such as a gun, knife, or club?" Positive relationships, such as family support, peers/others support and school connectedness, were evaluated using 13 adapted items from CIDI 3.0 (Kessler \& Ustün, 2004), the Psychological Sense of School Membership Scale (Goodenow, 1993), the Adverse Childhood Experience Scale (Felitti et al., 1998), and the Childhood Trauma Questionnaire (Bernstein, Ahluvalia, Pogge, \& 
Handelsman, 1997). Scales' scores were categorized into tertiles (high, middle or low) for the analysis after having checked that the linearity assumption of the logit in the continuous variables was not fulfilled. The least positive relationship category was the reference.

\section{$\underline{\text { Socio-demographics and educational }}$}

These factors included gender, center, and academic field, country of birth, parents' studies and living location at first term (parents' home or others).

\section{Analysis}

Missing values were imputed with multiple imputation (MI) ( $\mathrm{n}=5$ imputations $)$ using a fully conditional specification method. Pooled estimates from multiple imputations and MI-based standard errors taking into account within imputation and between imputation variances were obtained (Van Buuren, 2012). Inverse-probability weighting was applied to hard-to-reach respondents that were randomly selected in the second sampling stage (endgame strategy weights). Post-stratification weighting was used to adjust for differences between respondents and population distribution of sex, country of birth, academic field and university. Descriptive analyses were performed. Twelve-month prevalence of ideation, plan and attempt, stratified by gender, was estimated.

Risk and protective factors were classified on a modification of the socio-ecological model from the WHO (World Health Organization, 2014). As the model states, categories are not mutually exclusive, and factors can contribute to STB directly and indirectly by interrelating between them. Understanding the categories moving from systemic to individual represents a more useful approach. While previous analyses of UNIVERSAL project used a distal/proximal-factor epidemiological model (Blasco et al., 2019), a gender approach of suicidal risk does not correspond to a linear model and WHO socioecological model may be more adequate and complementary.

Bivariate analyses were performed to examine the associations of selected candidate risk and protective factors and 12-month STB. Crude ORs and 95\% Confidence Intervals (CI) were estimated and differences across subgroups (e.g., parent deceased yes vs. no) were evaluated using MI-based Wald statistic. Gender-differences in the associations between candidate predictors and 12-month STB were assessed using multiple logistic regression models including, one at a time, a gender-interaction term with 
each factor. Based on those results, gender-stratified multiple logistic regression models of 12-month STB were built adjusting by center, academic field, parents' university studies and living at first term. Group Lasso regularization was applied for the selection of variables to be included in the final multivariable models. Analyses excluded variables that showed low numbers within cells. Statistical significance was evaluated with a two-sided F-test based on multiple imputations and level of significance of 0.05. SAS software version 9.4 was used. Although we aimed to evaluate STB, due to low prevalence of suicide plan and attempts, we were not able to calculate its risk estimates. Only estimates of SI are presented.

\section{RESULTS}

A total sample of 2,105 students were included, with more than half being female $(55.4 \%$, weighted restored proportion of $72.4 \%$ ). Suicidal ideation (SI) and suicide plans showed a higher likelihood among females (Females: 10.5\% SI; 6.4\% plans. Males: 9.2\% SI; $4.8 \%$ plans), while suicide attempts were more frequent among males (Females: 0.5\%. Males: 0.9\%).

Some negative life events, recent stressful experiences and family adversities, among females and males, were as follows: dating violence (Females 8.9\%; Males 3.2\%); parental psychopathology $(33.5 \% ; 28 \%$ ) and stressors related to romantic partner $(31.5 \% ; 23.8 \%)$. Mood $(28.8 \% ; 18.1 \%)$ and anxiety $(25.8 \%$; $12.7 \%$ ) disorders were almost twice more frequent among females. Males reported a higher alcohol or substance abuse disorder than females (Females 7.5\%; Males 13.4\%), as well as physical maltreatment $(8.8 \% ; 11.3 \%)$, physical bully victimization $(4 \% ; 9.5 \%)$ and seriously physically assault $(2.6 \% ; 8.1 \%)$. In contrast, females showed higher family support $(39 \% ; 30.5 \%)$ and peers/others support $(30.1 \% ; 25.9 \%)$ (Table 1).

-- Insert Table 1 --

Table 2 shows bivariate associations of risk and protective factors with 12-month SI, stratified by gender. Common risk factors of SI for both genders included: mood disorders, childhood maltreatment and verbal bully victimization. Among stressful experiences in the last 12 months, common risk factors for both genders were betrayal, arguments or breakup with friends or family members (Females: OR 2.4; 95\%CI 1.6-3.6; p-value<.01. Males: OR 3.5; 95\%CI 2.1-5.6; p-value<.01), interpersonal conflicts (Females: OR 
2.1; 95\%CI 1.2-3.6; p-value<.01. Males: OR 1.8; 95\%CI 1.1-2.9; p-value=.02) and parental psychopathology (Females: OR 2.2; 95\%CI 1.5-3.2; p-value<.01. Males: OR 3.4; 95\%CI 2.1-5.3; pvalue<.01). For males only, SI was associated with parents' university studies (OR 2.4; 95\% 1.3-4.3; pvalue=.01), and hopelessness (OR 12.7; 95\%CI 6.1-26.3; p-value<.01). Positive relationships (high family, peers support and high school connectedness) were significantly associated to a lower SI risk for both genders.

-- Insert Table 2 -

Table 3 shows gender-specific risk and protective factors associated with 12-month SI adjusting for socio-demographic variables. Mood disorder predicted 12-month SI for both genders (Females: OR 5.5; 95\%CI 3.3-9.3; p-value<.01; Males: OR 4.4; 95\%CI 2.0-9.7; p-value<.01), with no gender-interaction. Females exposed to violence between parents had higher odds of 12 -month SI (OR 3.5; 95\%CI 1.7-7.2; pvalue<.01), whereas unexpected protective effect was seen for males (OR $0.3 ; 95 \%$ CI $0.1-0.9 ; p$ value $=.03$ ) with significant gender-interaction ( $p$-value $<0.01)$. Anxiety disorder (OR 2.7; 95\%CI 1.6-4.6; $p$-value <.01) and alcohol or substance disorder (OR 2.1; 95\%CI 1.1-4.3; $p$-value=.04) also increased SI risk among females, gender-interaction was observed for anxiety disorder $(p$-value $<0.01)$. Exposure to physical childhood maltreatment (OR 3.6; 95\%CI 1.4-9.2; p-value<.01), death of any of the parents (OR 4.6 95\%CI 1.2-17.7; p-value=.03), parental psychopathology (OR 2.4; 95\%CI 1.1-5.1; $p$-value=.03) and hopelessness (Agree strongly/moderate OR 7.7; 95\%CI 2.8-21.2; p-value<.01) were predictors of 12month SI in males. Except for hopelessness ( $p$-value=.02), these gender-interactions were not significant. Family support (High: OR 0.5; 95\%CI 0.2-0.9; Middle: OR 0.4; 95\%CI 0.2-0.7; p-value<.01) and peers/others support (Middle: OR 0.4; 95\%CI 0.2-0.8; p-value=.01) were protective factors only for females. Chronic health conditions reduced SI risk among males (OR 0.3; 95\%CI 0.1-0.8; $p$-value=.02) with significant gender-interaction ( $p$-value=.04). 


\section{DISCUSSION}

\section{Main findings}

The present study assessed gender-differences in suicidal ideation (SI) and in SI risk and protective factors among Spanish university students. Females presented SI and plans more often than males, while suicide attempts were more prevalent among males, which was consistent with previous reports (Cash \& Bridge, 2009; Eaton et al., 2012). Mood disorders were the only common risk factor of SI for both genders. Others risk factors assessed for the whole sample were specific either for females or males only. Among females, anxiety disorder, alcohol or substance disorder and violence between parents were major risk factors, with significant gender-interaction for anxiety and violence between parents. Hopelessness, physical childhood maltreatment, deceased parents and parental psychopathology were male-specific risk factors, with significant gender-interaction for hopelessness. Family and peers/others support were SI protective factors for females, with gender-interaction for family support. Surprisingly, violence between parents and chronic health conditions decreased SI risk among males. A comparative cross-gender summary of the magnitude of the association between significant risk and protective factors is presented in Table 4.

\section{-- Insert Table 4 -}

\section{Strengths and limitations}

This is the first original study systematically assessing gender-differences and interaction in a wide range of SI risk and protective factors among Spanish university students. Moreover, being part of the World Mental Health International College Survey (WMH-ICS) facilitates future comparisons and analyses.

Several limitations of this study deserve attention. First, although a convenience sample of universities was included, potentially limiting generalizability of our study's findings, geographical dispersion over Spain was considered. In fact, population's characteristics of the participating universities are similar to that of the overall Spanish university students. Also, low response rate and high proportion of females on the final respondents could limit representativeness. However, population-based adjustments through post-stratification and inverse probability weighting were applied to restore it (Brick, 2013). Second, the low number of individuals in some of the target factors limited the possibility to compare their association 
with SI for females and males when these variables were included in the models. Third, although our goal was to evaluate STB, low frequencies of suicide plans and attempts did not allow us to estimate multivariable logistic regression models for these outcomes. Therefore, only SI results are reported. However, for both genders, SI is one of the main predictors of suicidal behaviors; its assessment and prevention are of high concern. Moreover, we identified significant gender-interactions with some SI risk factors. Nevertheless, studies with larger samples, including higher number of males, are necessary to obtain a more reliable assessment of STB gender-differences. Fourth, results are based on self-reported data, without a clinical interview. It is unknown to what extent these two sources coincide but we addressed this limitation by undergoing a clinical re-appraisal study to control the validity of the research, which indicates a good concordance with these results (Ballester et al., 2019). Fifth, analyses according to sexual orientation were not performed and transsexual individuals were excluded. We are aware there are important suicidal risk differences among sexual minorities and we have reported some of them in a recent systematic review of the literature (Miranda-Mendizábal et al., 2017). To assess these issues, a specific paper based on the UNIVERSAL project survey will be performed. Finally, associations found cannot be considered as causal due to the cross-sectional nature of the data. Longitudinal studies are needed to determine causality.

\section{Comparisons with other studies}

Mood disorders are one of the most prevalent mental disorders among university students (Auerbach et al., 2016). Our results indicated that lifetime major depression and bipolar disorders are the only risk factors for SI common for both genders, accordingly with previous literature (Skogman, Alsén, \& Öjehagen, 2004). Alcohol and substance disorder and anxiety disorder were strongly associated to SI only among females, with significant gender-interaction for the latter. Previous findings showed strong correlation between anxiety and SI among university students (O’Neill et al., 2018) and specifically among females (Goel et al., 2018). Probable gender-differences in the association between anxiety and SI might be implied based on interaction results. Our findings about the association between alcohol/substance disorder and SI among females are novel. Previous research has shown no increased risk of SI associated to alcohol/substance abuse among university students. However, those analyses were not specific for either male or female students. Anxiety is strongly associated with severe impairment (e.g. university-related problems) (Alonso et al., 2018). Meanwhile, the effects of alcohol/substance 
use/abuse include failure in developmental tasks (e.g. healthy interaction with peers) and in daily obligations (e.g., attending school); and impair users' judgment (Mann, 2003; P.-W. Wang \& Yen, 2017).

A gender-interaction was observed for hopelessness, and increased risk of SI was observed only for males. Previous research has consistently found that hopelessness increased SI risk (Lane \& Miranda, 2018) or mediates the relationship of some other risk factors with SI (Abdollahi, Abu Talib, Siti Nor, \& Zanariah, 2016; Lamis, Ballard, May, \& Dvorak, 2016). However, there is lack of evidence about the association between hopelessness and STB according to gender among university students, showing the need of further studies.

Protective effect from family and peers/others support for SI among females was observed, being consistent with previous literature (Cash \& Bridge, 2009; Macalli et al., 2018; Miller, Esposito-Smythers, \& Leichtweis, 2015). Higher levels of support exert its protective effect by increasing self-efficacy or reducing stress (Arria et al., 2009; Thompson et al., 2000). Unexpected results observed in the association between violence between parents and chronic health conditions or physical impairment with SI are probably due to low numbers in these and some other variables included in the model. Further analyses that include wider samples and higher number of males are needed to draw robust conclusions.

\section{Implications for prevention and future research}

Our findings contribute substantially to the existing literature on gender-differences in SI risk and protective factors. A profound knowledge of SI gender-risk factors might help increasing awareness about students who could be at serious risk. Results showed gender-interactions with some mental disorders and psychological factors; which have a profound impact on students' physical, emotional, cognitive and interpersonal functioning, affecting their academic performance, retention and graduation rates (Kitzrow, 2009).

Students' mental health should be a priority for universities. A prompt detection of high-risk suicidal cases may reduce suicide mortality (Paschall \& Bersamin, 2018). Gatekeeper prevention interventions are an example of intervention at university campuses to improve knowledge, skills and self-efficacy regarding suicide intervention to identify and potentially help suicidal students. There is little evidence about interventions on treatment referrals for students with STB, and studies do not address the 
effectiveness of the treatment in STB (Wolitzky-Taylor, LeBeau, Perez, Gong-Guy, \& Fong, 2019). A combination of individual strategies building personal skills and setting-based approach to improve the overall university setting has also been recommended (Fernandez et al., 2016). Ensuring self-regulation and coping strategies prior to the onset of university stressful life events might be helpful (O'Neill et al., 2018). Although suicide prevention in universities has increased, there is still room for improvement. Research addressing effectiveness of interventions to reduce the frequency and intensity of STB, or to change help-seeking behavior and linkage to treatment, as well as secondary and tertiary STB prevention, is needed.

Gender-differences when engaging into preventive strategies also should be taken into account. Females are more willing to communicate and to use prevention centers (Klimes-Dougan, Yuan, Lee, \& Houri, 2009). Accordingly, the benefit from school-based programs (Kalafat \& Gagliano, 1996) and screening at primary care settings (Rutz, von Knorring, \& Wålinder, 1992) is evident. Males are not prone to be actively involved in suicide awareness programs (Shaffer, Vieland, \& Garland, 1990). School-wide screening (Garlow., 2008) and public campaigns (Daigle et al., 2006) may facilitate STB identification among them.

Further research is needed in several areas. In this study, no attempt has been made to interpret the causal associations between the evaluated factors. Future longitudinal research to clarify the mechanisms underlying gender-differences, mediator variables and possible pathways of STB development is required. Tests for analyzing significant interactions/effects or techniques for more accurate baseline screening algorithms are also needed. Finally, improving quantity and quality of research about preventive strategies of STB in university settings is desirable. 


\section{REFERENCES}

Abdollahi, A., Abu Talib, M., Siti Nor, Y., \& Zanariah, I. (2016). Problem-Solving Skills and Suicidal Ideation Among Malaysian College Students: the Mediating Role of Hopelessness. Academic Psychiatry, 40(2), 261.

Alonso, J., Mortier, P., Auerbach, R. P., Bruffaerts, R., Vilagut, G., Cuijpers, P., ... Kessler, R. C. (2018). Severe role impairment associated with mental disorders: Results of the WHO World Mental Health Surveys International College Student Project. Depression and Anxiety, 1-13. http://doi.org/10.1002/da.22778

Arria, A. M., O’Grady, K. E., Caldeira, K. M., Vincent, K. B., Wilcox, H. C., \& Wish, E. D. (2009). Suicide ideation among college students: A multivariate analysis. Archives of Suicide Research, 13(3), 230-246. http://doi.org/10.1080/13811110903044351

Ashrafioun, L., Bonar, E., \& Conner, K. R. (2016). Health attitudes and suicidal ideation among university students. Journal of American College Health, 64(3), 256-60. http://doi.org/10.1080/07448481.2015.1081911

Auerbach, R., Alonso, J., Axinn, W., Cuijpers, P., Ebert, D., Greif Green, J., ... Bruffaerts, R. (2016). Mental disorders among college students in the WHO World Mental Health Surveys. Psychological Medicine, 46(14), 2955-2970. http://doi.org/10.1017/S0033291716001665

Ballester, L., Alayo, I., Vilagut, G., Almenara, J., Cebrià, A. I., Echeburúa, E., ... Alonso, J. (2019). Accuracy of online survey assessment of mental disorders and suicidal thoughts and behaviors in Spanish university students. Results of the WHO World Mental Health-International College Student initiative. Plos One, 14(9), e0221529. https://doi.org/10.1371/journal.pone.0221529

Beck, A. T., Weissman, A., Lester, D., \& Trexler, L. (1974). The measurement of pessimism: The hopelessness scale. Journal of Consulting and Clinical Psychology, 42(6), 861-865.

Bernstein, D. P., Ahluvalia, T., Pogge, D., \& Handelsman, L. (1997). Validity of the childhood trauma questionnaire in an adolescent psychiatric population. Journal of the American Academy of Child and Adolescent Psychiatry, 36(3), 340-348. http://doi.org/10.1097/00004583-199703000-00012

Blasco, M., Castellví, P., Almenara, J., Lagares, C., Roca, M., Sesé, A., ... Auerbach, R. P. (2016).

Predictive models for suicidal thoughts and behaviors among Spanish University students : rationale and methods of the UNIVERSAL (University \& mental health) project. BMC Psychiatry, 16(122), 1-13. http://doi.org/10.1186/s12888-016-0820-y

Blasco, M., Vilagut, G., Almenara, J., Roca, M., Piqueras, J. A., Gabilondo, A., ... Alonso, J. (2019). Suicidal Thoughts and Behaviors: Prevalence and Association with Distal and Proximal Factors in Spanish University Students. Suicide and Life-Threatening Behavior, 49(3), 881-898. http://doi.org/10.1111/sltb.12491

Boyd, A., Van De Velde, S., Vilagut, G., De Graaf, R., O’Neill, S., Florescu, S., ... Kovess-Masfety, V. (2015). Gender differences in mental disorders and suicidality in Europe: Results from a large cross-sectional population-based study. Journal of Affective Disorders, 173, 245-254. 
http://doi.org/10.1016/j.jad.2014.11.002

Bray, R., Pemberton, M., Hourani, L., Witt, M., Olmsted, K., \& Brown, J. (2009). 2008 Department of defense survey of health related behaviors among active duty military personnel. North Carolina: Research Triangle Institute, Research Triangle Park.

Brick, J. M. (2013). Unit Nonresponse and Weighting Adjustments: A Critical Review. Journal of Official Statistics, 29(3), 329-353. http://doi.org/10.2478/jos-2013-0026

Brugha, T., \& Cragg, D. (1990). The List of Threatening Experiences: the reliability and validity of a brief life events questionnaire. Acta Psychiatrica Scandinavica, 82, 77-81.

Canetto, S. S., \& Sakinofsky, I. (1998). The Gender Paradox in Suicide. Suicide and Life-Threatening Behavior, 28(1), 1-23.

Cash, S., \& Bridge, J. (2009). Epidemiology of Youth Suicide and Suicidal Behavior. Current Opinion in Pediatrics, 21(5), 613-619. http://doi.org/10.1097/MOP.0b013e32833063e1

Daigle, M., Beausoleil, L., Brisoux, J., Raymond, S., Charbonneau, L., \& Desaulniers, J. (2006).

Reaching suicidal people with media campaigns: new challenges for a new century. Crisis, 27, 172180.

Eaton, D., Kann, L., \& Jinchen, S. (2012). Youth Risk Behavior Surveillance — United States, 2011. MMWR Surveill Summ, 61, 1-162.

Eskin, M., Sun, J.-M., Abuidhail, J., Yoshimasu, K., Kujan, O., Janghorbani, M., ... Voracek, M. (2016). Suicidal Behavior and Psychological Distress in University Students: A 12-nation Study. Archives of Suicide Research, 20(3), 369-388. http://doi.org/10.1080/13811118.2015.1054055

Felitti, V. J., Anda, R. F., Nordenberg, D., Williamson, D. F., Spitz, A. M., Edwards, V., ... Marks, J. S. (1998). Relationship of Childhood Abuse and Household Dysfunction to Many of the Leading Causes of Death in Adults The Adverse Childhood Experiences (ACE) Study. American Journal of Preventive Medicine, 14(4), 245-258.

Fernandez, A., Howse, E., Rubio-Valera, M., Thorncraft, K., Noone, J., Luu, X., ... Salvador-Carulla, L. (2016). Setting-based interventions to promote mental health at the university: a systematic review. International Journal of Public Health, 61(7), 797-807. http://doi.org/10.1007/s00038-016-0846-4

Garlow, S. J., Rosenberg, J., Moore, J. D., Haas, A. P., Koestner, B., Hendin, H., \& Nemeroff, C. B. (2008). Depression, desperation, and suicidal ideation in college students: Results from the American Foundation for Suicide Prevention College Screening Project at Emory University. Depression and Anxiety, 25(6), 482-488. http://doi.org/10.1002/da.20321

Goel, N. J., Sadeh-Sharvit, S., Flatt, R. E., Trockel, M., Balantekin, K. N., Fitzsimmons-Craft, E. E., ... Taylor, C. B. (2018). Correlates of Suicidal Ideation in College Women with Eating Disorders HHS Public Access. Int J Eat Disord, 51(6), 579-584. http://doi.org/10.1002/eat.22865

Goodenow, C. (1993). The psychological sense of school membership among adolescents: Scale development and educational correlates. Psychology in the Schools, 30(1). 
Holt, M., Vivolo-Kantor, A., Polanin, J., Holland, K., DeGue, S., Matjasko, J., ... Reid, G. (2015). Bullying and Suicidal Ideation and Behaviors: A Meta-Analysis. Pediatrics, 135(2), e496-e509. http://doi.org/10.1542/peds.2014-1864

Instituto Nacional de Estadísticas. (2015). Defunciones según la causa de muerte. Retrieved from http://www.ine.es/jaxiT3/Datos.htm?t=7947

Johnson, J. G., Cohen, P., Gould, M. S., Kasen, S., Brown, J., \& Brook, J. S. (2002). Childhood Adversities, Interpersonal Difficulties, and Risk for Suicide Attempts During Late Adolescence and Early Adulthood. Archives of General Psychiatry, 59, 741-749. http://doi.org/10.1001/archpsyc.59.8.741

Kalafat, J., \& Gagliano, C. (1996). The Use of Simulations to Assess the Impact of an Adolescent Suicide Response Curriculum. Suicide and Life-Threatening Behavior, 26(359-364).

Kessler, R. C., Farley, P. A., Gruber, M., Harshaw, Q., Jewell, M. A., Sampson, N., \& Shillington, A. C. (2010). PMH72 Concordance of computarized self-report measures of DSM-IV-TR mood and anxietydisorders compared to gold standard clinical assessments in prymary care. Value in Health, 13(3), A118. http://doi.org/10.1016/s1098-3015(10)72567-5

Kessler, R. C., \& Ustün, T. B. (2004). The World Mental Health (WMH) Survey Initiative Version of the World Health Organization (WHO) Composite International Diagnostic Interview (CIDI). International Journal of Methods in Psychiatric Research, 13(2), 93-121.

Kitzrow, M. A. (2009). The Mental Health Needs of Today’s College Students: Challenges and Recommendations. NASPA Journal, 46(4), 646-660.

Klimes-Dougan, B., Yuan, C., Lee, S., \& Houri, A. (2009). Suicide prevention with adolescents: considering potential benefits and untoward effects of public service announcements. Crisis, 30(3), $128-135$.

Lamis, D. A., Ballard, E. D., May, A. M., \& Dvorak, R. D. (2016). Depressive Symptoms and Suicidal Ideation in College Students: The Mediating and Moderating Roles of Hopelessness, Alcohol Problems, and Social Support. Journal of Clinical Psychology, 72(9), 919-32. http://doi.org/10.1002/jclp.22295

Lane, R., \& Miranda, R. (2018). The effects of familial acculturative stress and hopelessness on suicidal ideation by immigration status among college students. Journal of American College Health, 66(2), 76-86. http://doi.org/10.1080/07448481.2017.1376673

Macalli, M., Tournier, M., Galéra, C., Montagni, I., Soumare, A., Côté, S. M., \& Tzourio, C. (2018). Perceived parental support in childhood and adolescence and suicidal ideation in young adults: a cross-sectional analysis of the i-Share study. BMC Psychiatry, 18, 373. http://doi.org/10.1186/s12888-018-1957-7

Mann, J. J. (2003). Neurobiology of suicidal behaviour. Nature, 4(October), 819-828. http://doi.org/10.1038/nrn1220

Mergl, R., Koburger, N., Heinrichs, K., Székely, A., Tóth, D., Coyne, J., .. Mcdaid, D. (2015). What Are 
Reasons for the Large Gender Differences in the Lethality of Suicidal Acts? An Epidemiological Analysis in Four European Countries. PLOS ONE, 10(7), 1-18.

http://doi.org/10.1371/journal.pone.0129062

Miller, A. B., Esposito-Smythers, C., \& Leichtweis, R. N. (2015). Role of social support in adolescent suicidal ideation and suicide attempts. Journal of Adolescent Health, 56(3), 286-292.

http://doi.org/10.1016/j.jadohealth.2014.10.265

Miranda-Mendizabal, A., Castellví, P., Parés-Badell, O., Alayo, I., Almenara, J., Alonso, I., ... Alonso, J. (2019). Gender differences in suicidal behavior in adolescents and young adults: systematic review and meta-analysis of longitudinal studies. International Journal of Public Health, 64(2), 265-283. http://doi.org/10.1007/s00038-018-1196-1

Miranda-Mendizábal, A., Castellví, P., Parés-Badell, O., Almenara, J., Alonso, I., Blasco, M. J., ... Alonso, J. (2017). Sexual orientation and suicidal behaviour in adolescents and young adults: systematic review and meta-analysis. The British Journal of Psychiatry, 211, 77-87. http://doi.org/10.1192/bjp.bp.116.196345

Mortier, P., Auerbach, R. P., Alonso, J., Bantjes, J., Benjet, C., Cuijpers, P., ... Vives, M. (2018). Suicidal Thoughts and Behaviors Among First-Year College Students: Results From the WMH-ICS Project. Journal of the American Academy of Child and Adolescent Psychiatry, 57(4), 263-273.e1. http://doi.org/10.1016/j.jaac.2018.01.018

Navarro-Gómez, N. (2017). El suicidio en jóvenes en España: cifras y posibles causas. Análisis de los últimos datos disponibles. Clinica y Salud, 28(1), 25-31. http://doi.org/10.1016/j.clysa.2016.11.002

Nock, M., Holmberg, E., Photos, V., \& Michel, B. (2007). Self-Injurious Thoughts and Behaviors Interview: development, reliability, and validity in an adolescent sample. Psychology Assessment, 19(3), 309-17.

O’Neill, S., McLafferty, M., Ennis, E., Lapsley, C., Bjourson, T., Armour, C., ... Murray, E. (2018). Socio-demographic, mental health and childhood adversity risk factors for self-harm and suicidal behaviour in College students in Northern Ireland. Journal of Affective Disorders, 239, 58-65. http://doi.org/10.1016/j.jad.2018.06.006

Paschall, M. J., \& Bersamin, M. (2018). School-Based Health Centers, Depression, and Suicide Risk Among Adolescents. American Journal of Preventive Medicine, 54(1), 44-50. http://doi.org/10.1016/j.amepre.2017.08.022

Pedrelli, P., Nyer, M., Yeung, A., Zulauf, C., \& Wilens, T. (2015). College Students: Mental Health Problems and Treatment Considerations. Academic Psychiatry, 39(5), 503-511. http://doi.org/10.1007/s40596-014-0205-9

Posner, K., Oquendo, M. A., Gould, M., Stanley, B., \& Davies, M. (2007). (C-CASA): Classification of Suicidal Events in the FDA's Pediatric Suicidal Risk Analysis of Antidepressants. Psychiatry: Interpersonal and Biological Processes, 164, 1035-1043. http://doi.org/10.1176/ajp.2007.164.7.1035 
Rutz, W., von Knorring, L., \& Wålinder, J. (1992). Long-term effects of an educational program for general practitioners given by the Swedish Committee for the Prevention and Treatment of Depression. Acta Psychiatrica Scandinavica, 85(1), 83-8.

Saunders, J. B., Aasland, O. G., Babor, T. F., de la Fuente, J. R., \& Grant, M. (1993). Development of the Alcohol Use Disorders Identification Test (AUDIT): WHO collaborative project on early detection of persons with harmful alcohol consumption. Addiction, 88, 791-804. http://doi.org/10.1111/j.1360-0443.1993.tb02093.x

Shaffer, D., Vieland, V., \& Garland, A. (1990). Adolescent Suicide Attempters. Response to SuicidePrevention Programs. JAMA, 264, 3151-3155.

Skogman, K., Alsén, M., \& Öjehagen, A. (2004). Sex differences in risk factors for suicide after attempted suicide. Social Psychiatry and Psychiatric Epidemiology, 39(2), 113-120. http://doi.org/10.1007/s00127-004-0709-9

Swearer, S. M., \& Cary, P. T. (2003). Perceptions and Attitudes Toward Bullying in Middle School Youth. Journal of Applied School Psychology, 19(2), 63-79. http://doi.org/10.1300/J008v19n02_05

Thompson, E., Eggert, L. L., \& Herting, J. R. (2000). Mediating effects of an indicated prevention program for reducing youth depression and suicide risk behaviors. Suicide and Life-Threatening Behavior, 30(3), 252-271.

Van Buuren, S. (2012). Flexible imputation of missing data (2nd ed.). New York, EEUU: CRC Press.

Värnik, A., Kõlves, K., van der Feltz-Cornelis, C., Marusic, A., Oskarsson, H., Palmer, A., ... Hegerl, U. (2008). Suicide methods in Europe: a gender-specific analysis of countries participating in the “European Alliance Against Depression”. Journal of Epidemiology \& Community Health, 62(6), 545-551. http://doi.org/10.1136/jech.2007.065391

Vogt, D. S., Proctor, S. P., King, D. W., King, L. A., \& Vasterling, J. J. (2008). Validation of Scales From the Deployment Risk and Resilience Inventory in a Sample of Operation Iraqi Freedom Veterans, $391-403$.

Wang, L., He, C. Z., Yu, Y. M., Qiu, X. H., Yang, X. X., Qiao, Z. X., ... Yang, Y. J. (2014). Associations between impulsivity, aggression, and suicide in Chinese college students. BMC Public Health, 14(1), 551. http://doi.org/10.1186/1471-2458-14-551

Wang, P.-W., \& Yen, C.-F. (2017). Adolescent substance use behavior and suicidal behavior for boys and girls: a cross-sectional study by latent analysis approach. BMC Psychiatry, 17(1), 392. http://doi.org/10.1186/s12888-017-1546-1

Werbart Törnblom, A., Werbart, A., \& Rydelius, P.-A. (2015). Shame and gender differences in paths to youth suicide: Parents' perspective. Qualitative Health Research, 25(8), 1099-1116. http://doi.org/10.1177/1049732315578402

Wolitzky-Taylor, K., LeBeau, R. T., Perez, M., Gong-Guy, E., \& Fong, T. (2019). Suicide prevention on college campuses: What works and what are the existing gaps? A systematic review and metaanalysis. Journal of American College Health, 1-11. 
http://doi.org/10.1080/07448481.2019.1577861

World Health Organization. (2014). Preventing suicide, a global imperative. Geneva. Retrieved from:

https://apps.who.int/iris/bitstream/handle/10665/131056/9789241564779_eng.pdf;jsessionid=E139

B4420CB5185DDEAF4FCBA4B29781? sequence $=1$

World Health Organization. (2016). Suicide data. Retrieved from:

http://www.who.int/mental_health/prevention/suicide/suicideprevent/en/ 
Table 1. Socio-demographic, individual, community risk, and protective factors of the students included in the analysis (absolute numbers and weighted proportions). The UNIVERSAL (University and Mental Health) project

\begin{tabular}{|c|c|c|c|c|c|c|c|}
\hline & & \multicolumn{2}{|c|}{$\begin{array}{l}\text { TOTAL } \\
\mathbf{n}=2,105\end{array}$} & \multicolumn{2}{|c|}{$\begin{array}{c}\text { FEMALE } \\
\mathbf{n}=\mathbf{1 , 5 2 5}\end{array}$} & \multicolumn{2}{|c|}{$\begin{array}{c}\text { MALE } \\
\mathbf{n}=\mathbf{5 8 0}\end{array}$} \\
\hline & & n & $\%$ & $\mathbf{n}$ & $\%$ & n & $\%$ \\
\hline \multicolumn{8}{|c|}{ SOCIO-DEMOGRAPHICS AND EDUCATIONAL } \\
\hline \multirow[t]{5}{*}{ Centre } & Balearic Islands University (UIB) & 300 & 12.4 & 238 & 13.1 & 62 & 11.5 \\
\hline & Basque Country University (UPV-EHU) & 636 & 43.8 & 449 & 42.1 & 187 & 45.8 \\
\hline & Cadiz University (UCA) & 297 & 19.7 & 208 & 20.1 & 89 & 19.2 \\
\hline & Miguel Hernández University (UMH) & 291 & 10.5 & 185 & 9.5 & 106 & 11.7 \\
\hline & Pompeu Fabra University (UPF) & 581 & 13.6 & 445 & 15.1 & 136 & 11.7 \\
\hline \multirow[t]{5}{*}{ Academic Field } & Arts and Humanities & 240 & 9.8 & 211 & 12 & 29 & 7 \\
\hline & Engineering and Architecture & 290 & 18.6 & 121 & 8 & 169 & 31.7 \\
\hline & Health Sciences & 541 & 15.6 & 425 & 20 & 116 & 10.1 \\
\hline & Science & 202 & 8.4 & 127 & 8 & 75 & 8.9 \\
\hline & Social and Legal Sciences & 832 & 47.6 & 641 & 51.9 & 191 & 42.3 \\
\hline \multirow[t]{2}{*}{ Country of birth } & Spain & 1951 & 94.8 & 1411 & 95.1 & 540 & 94.4 \\
\hline & Other & 154 & 5.2 & 114 & 4.9 & 40 & 5.6 \\
\hline \multirow[t]{2}{*}{ Parent's studies } & At least one & 950 & 42.8 & 676 & 41.4 & 275 & 44.5 \\
\hline & Neither & 1155 & 57.2 & 849 & 58.6 & 305 & 55.5 \\
\hline \multirow[t]{2}{*}{ Living at first term } & Parents home & 1185 & 56.2 & 842 & 52.5 & 343 & 60.6 \\
\hline & Other & 920 & 43.8 & 683 & 47.5 & 237 & 39.4 \\
\hline \multicolumn{8}{|c|}{ NEGATIVE LIFE EVENTS AND FAMILY ADVERSITY } \\
\hline \multirow[t]{5}{*}{ Childhood maltreatment } & Emotional & 470 & 20.8 & 348 & 21.6 & 122 & 19.7 \\
\hline & Physical & 218 & 9.9 & 148 & 8.8 & 70 & 11.3 \\
\hline & Sexual & 35 & 1.7 & 28 & 2.4 & 8 & 0.8 \\
\hline & Neglect & 173 & 7.5 & 121 & 7.3 & 52 & 7.9 \\
\hline & Any & 596 & 27.2 & 429 & 26.6 & 167 & 28 \\
\hline \multirow[t]{4}{*}{ Bully victimization } & Physical & 131 & 6.4 & 70 & 4 & 60 & 9.5 \\
\hline & Verbal & 654 & 30.8 & 471 & 29.6 & 184 & 32.2 \\
\hline & Cyber & 69 & 3 & 58 & 3.2 & 11 & 2.7 \\
\hline & Any & 670 & 31.5 & 483 & 30.2 & 187 & 33.1 \\
\hline Dating violence & Yes & 169 & 6.4 & 146 & 8.9 & 23 & 3.2 \\
\hline \multirow[t]{6}{*}{ Family adversity } & Any parents deceased & 78 & 3.8 & 56 & 3.7 & 21 & 3.9 \\
\hline & Parents separation or divorce & 367 & 13.8 & 286 & 16.3 & 82 & 10.7 \\
\hline & Parental psychopathology & 707 & 31 & 521 & 33.5 & 186 & 28 \\
\hline & Attempted or died by suicide & 62 & 2.6 & 40 & 2.5 & 22 & 2.7 \\
\hline & Violence between parents & 217 & 9.5 & 152 & 9.1 & 65 & 10 \\
\hline & Parental criminal activities & 50 & 2.2 & 36 & 2 & 14 & 2.5 \\
\hline \multicolumn{8}{|c|}{ RECENT STRESSFUL EXPERIENCES (12-MONTH) } \\
\hline & $\begin{array}{l}\text { Death, life-threatening illness or injury } \\
\text { of a friend or family member }\end{array}$ & 1106 & 51.6 & 819 & 55.1 & 287 & 47.3 \\
\hline & $\begin{array}{l}\text { Stressors related to romantic partner } \\
\text { (break-up or cheated) }\end{array}$ & 633 & 28 & 478 & 31.5 & 155 & 23.8 \\
\hline & $\begin{array}{l}\text { Betrayal, arguments or break up with } \\
\text { friends or family member }\end{array}$ & 959 & 45.8 & 745 & 50.6 & 215 & 40 \\
\hline & Interpersonal conflicts & 218 & 13.5 & 121 & 8.5 & 97 & 19.8 \\
\hline & Life-threatening accident & 90 & 5.3 & 49 & 2.6 & 41 & 8.6 \\
\hline & Seriously physically assaulted & 81 & 5.1 & 40 & 2.6 & 41 & 8.1 \\
\hline & Sexually assaulted or raped & 12 & 0.5 & 11 & 0.8 & 1 & 0.3 \\
\hline
\end{tabular}




\begin{tabular}{|c|c|c|c|c|c|c|c|}
\hline & $\begin{array}{l}\text { Trouble with the police or serious legal } \\
\text { problems }\end{array}$ & 57 & 5.6 & 15 & 1.3 & 41 & 11 \\
\hline & Other stressful experience & 151 & 6.6 & 118 & 6.3 & 32 & 6.9 \\
\hline & Any past year stressful experiences & 1677 & 79.5 & 1240 & 82.6 & 437 & 75.7 \\
\hline \multicolumn{8}{|l|}{ INDIVIDUAL } \\
\hline \multirow[t]{4}{*}{ Mental disorders ${ }^{\dagger}$} & Mood disorder & 598 & 24 & 465 & 28.8 & 133 & 18.1 \\
\hline & Anxiety disorder & 509 & 19.9 & 418 & 25.8 & 91 & 12.7 \\
\hline & Alcohol or substance disorder & 172 & 10.1 & 109 & 7.5 & 63 & 13.4 \\
\hline & Any mental disorder & 867 & 37.1 & 675 & 41.4 & 192 & 31.7 \\
\hline \multicolumn{8}{|l|}{ Psychological } \\
\hline \multirow[t]{3}{*}{ Hopelessness } & Agree strongly/moderate & 297 & 14 & 229 & 16.3 & 68 & 11.2 \\
\hline & Neither agree or disagree & 949 & 45.9 & 692 & 44.1 & 257 & 48.2 \\
\hline & Disagree strongly/moderate & 859 & 40 & 604 & 39.6 & 255 & 40.6 \\
\hline $\begin{array}{l}\text { Chronic health conditions or } \\
\text { physical impairment }\end{array}$ & & 403 & 20.7 & 296 & 22.5 & 107 & 18.5 \\
\hline \multicolumn{8}{|l|}{ COMMUNITY } \\
\hline Access to means & Yes & 52 & 2.7 & 22 & 1.1 & 30 & 4.7 \\
\hline \multicolumn{8}{|l|}{ Positive Relationships : } \\
\hline \multirow[t]{3}{*}{ Family support } & High & 818 & 35.2 & 638 & 39 & 179 & 30.5 \\
\hline & Middle & 707 & 34.8 & 486 & 34.7 & 221 & 34.9 \\
\hline & Low & 581 & 30 & 401 & 26.2 & 180 & 34.6 \\
\hline \multirow[t]{3}{*}{ Peers/others support } & High & 589 & 28.2 & 457 & 30.1 & 132 & 25.9 \\
\hline & Middle & 849 & 36.7 & 633 & 38.3 & 216 & 34.8 \\
\hline & Low & 667 & 35.1 & 435 & 31.6 & 231 & 39.4 \\
\hline \multirow[t]{3}{*}{ School connectedness } & High & 617 & 29.1 & 453 & 28.6 & 164 & 29.7 \\
\hline & Middle & 813 & 37.7 & 579 & 37.8 & 233 & 37.6 \\
\hline & Low & 675 & 33.2 & 493 & 33.6 & 183 & 32.7 \\
\hline
\end{tabular}

$†$ Mood includes Major Depression or Bipolar; Anxiety includes Panic Disorder or Generalized Anxiety Disorder; Alcohol or substance includes abuse or dependence.

+ Family support lowest tertile [1-3.75], middle tertile [4-4.5], highest tertile [4.75-5]. Peers/others support lowest tertile [1-2.75], middle tertile [3-3.5], highest tertile [3.75-5]. School connectedness lowest tertile [1.17-3.33], middle tertile [3.5-4.17], highest tertile [4.33-5]. 
Table 2. Bivariate associations between risk and protective factors with 12-month suicidal ideation among Spanish university students, stratified by sex. The UNIVERSAL (University and Mental Health) project.

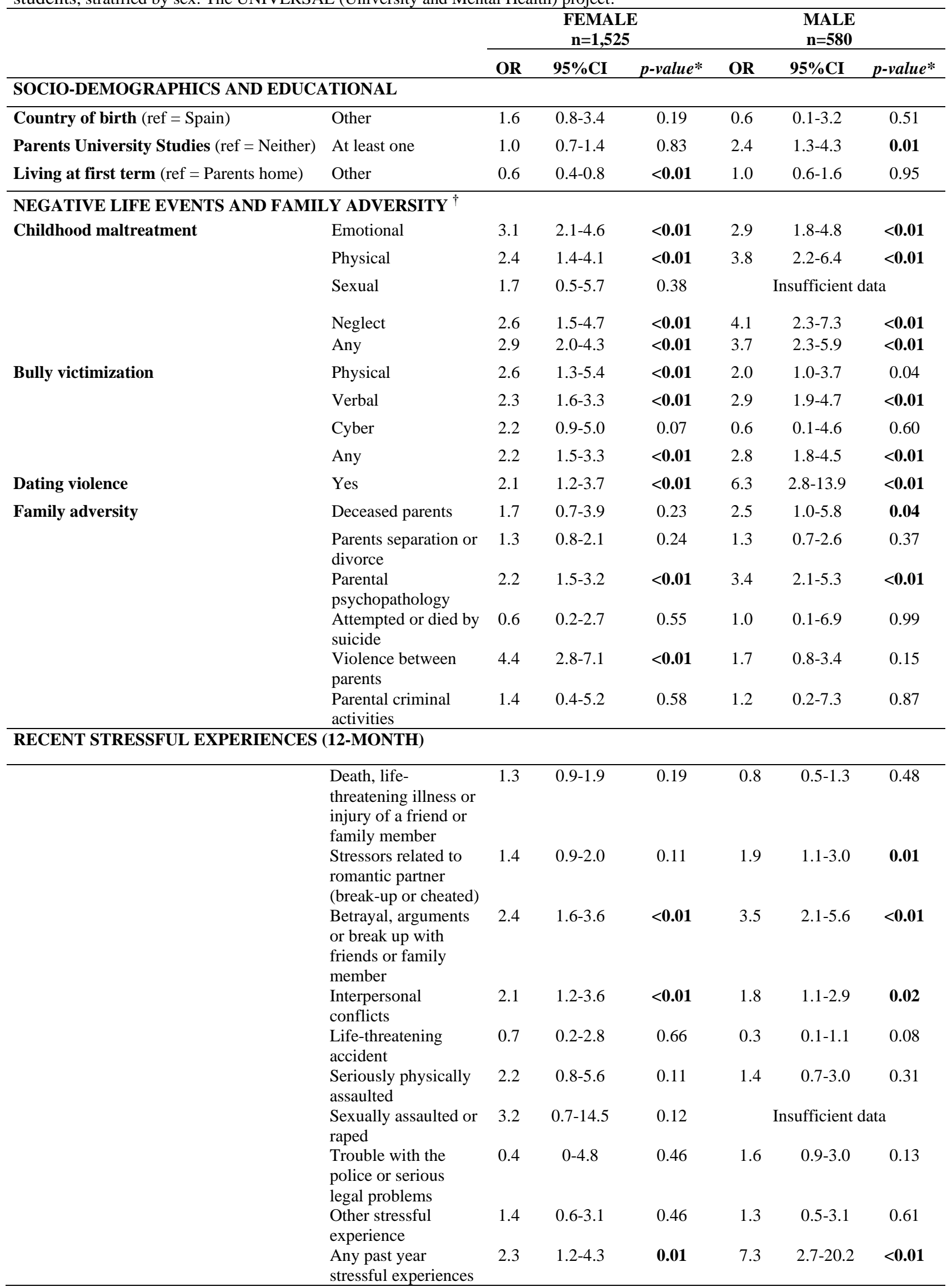


Table 2 (continued)

\begin{tabular}{|c|c|c|c|c|c|c|c|}
\hline INDIVIDUAL & & & & & & & \\
\hline \multirow[t]{4}{*}{ Mental disorders ${ }^{\dagger *}$} & Mood disorder & 9.7 & $6.3-15$ & $<0.01$ & 7.3 & $4.6-11.8$ & $<0.01$ \\
\hline & Anxiety disorder & 5.6 & $3.8-8.4$ & $<0.01$ & 2.0 & $1.1-3.5$ & 0.02 \\
\hline & $\begin{array}{l}\text { Alcohol or substance } \\
\text { disorder }\end{array}$ & 2.3 & $1.3-4.0$ & $<0.01$ & 2.2 & $1.3-3.9$ & $<0.01$ \\
\hline & Any mental disorder & 15.6 & $8.5-28.8$ & $<0.01$ & 3.9 & $2.4-6.2$ & $<0.01$ \\
\hline \multicolumn{8}{|l|}{ Psychological } \\
\hline \multirow[t]{2}{*}{$\begin{array}{l}\text { Hopelessness }(\text { ref }=\text { Disagree } \\
\text { strongly/moderate) }\end{array}$} & $\begin{array}{l}\text { Agree } \\
\text { strongly/moderate }\end{array}$ & 3.4 & $2.1-5.6$ & $<0.01$ & 12.7 & $6.1-26.3$ & $<0.01$ \\
\hline & $\begin{array}{l}\text { Neither agree or } \\
\text { disagree }\end{array}$ & 1.2 & $0.8-1.9$ & & 3.4 & $1.8-6.6$ & \\
\hline $\begin{array}{l}\text { Chronic health conditions or physical } \\
\text { impairment }{ }^{\dagger}\end{array}$ & & 1.2 & $0.7-1.8$ & 0.51 & 0.4 & $0.2-0.9$ & $\mathbf{0 . 0 3}$ \\
\hline \multicolumn{8}{|l|}{ COMMUNITY } \\
\hline Access to means $^{\dagger}$ & Yes & 4.1 & $1.2-13.4$ & 0.02 & 4.5 & $2.3-9.1$ & $<0.01$ \\
\hline \multicolumn{8}{|l|}{ Positive Relationships ${ }^{\S}$} \\
\hline \multirow[t]{2}{*}{ Family support $($ ref $=$ Low $)$} & High & 0.3 & $0.2-0.4$ & $<0.01$ & 0.1 & $0-0.3$ & $<0.01$ \\
\hline & Middle & 0.3 & $0.2-0.5$ & & 1.2 & $0.7-1.9$ & \\
\hline \multirow[t]{2}{*}{ Peers/others support (ref = Low) } & High & 0.5 & $0.3-0.7$ & $<0.01$ & 0.1 & $0.0-0.4$ & $<0.01$ \\
\hline & Middle & 0.3 & $0.2-0.5$ & & 0.9 & $0.5-1.4$ & \\
\hline \multirow[t]{2}{*}{ School connectedness $($ ref = Low $)$} & High & 0.4 & $0.2-0.6$ & $<0.01$ & 0.1 & $0.1-0.3$ & $<0.01$ \\
\hline & Middle & 0.4 & $0.2-0.6$ & & 0.5 & $0.3-0.9$ & \\
\hline
\end{tabular}

OR odds ratio; 95\% CI 95\% confidence interval; *p-values for F-test to evaluate significance of each categorical predictor based on multiple imputation. p-values <0.05 highlighted in bold.

$\uparrow$ Reference category: no.

+ Mood includes Major Depression or Bipolar; Anxiety includes Panic Disorder or Generalized Anxiety Disorder; Alcohol or substance includes abuse or dependence.

\$Family support lowest tertile [1-3.75], middle tertile [4-4.5], highest tertile [4.75-5]. Peers/others support lowest tertile [1-2.75], middle tertile [3-3.5], highest tertile [3.75-5]. School connectedness lowest tertile [1.17-3.33], middle tertile [3.5-4.17], highest tertile [4.33-5]. 
Table 3. Results of the multivariable models of gender-specific risk and protective factors of 12-month suicidal ideation among Spanish university students. The UNIVERSAL (University and Mental Health) project.

\begin{tabular}{|c|c|c|c|c|c|c|c|c|}
\hline & \multicolumn{3}{|c|}{ FEMALE } & \multicolumn{3}{|c|}{ MALE } & \multirow{2}{*}{$\begin{array}{c}p \text {-value for } \\
\text { intxn** }\end{array}$} \\
\hline & & OR & $95 \% \mathrm{CI}$ & $p$-value* & OR & $95 \% \mathrm{CI}$ & p-value* & \\
\hline \multicolumn{9}{|c|}{$\begin{array}{l}\text { NEGATIVE LIFE EVENTS AND FAMILY } \\
\text { ADVERSITY }{ }^{\dagger}\end{array}$} \\
\hline \multirow[t]{4}{*}{ Childhood maltreatment } & Emotional & 1.2 & $0.7-2.2$ & .49 & 1 & $0.4-2.4$ & .94 & .56 \\
\hline & Physical & 0.7 & $0.3-1.6$ & .39 & 3.6 & $1.4-9.2$ & $<.01$ & .48 \\
\hline & Neglect & --- & ---- & --- & 1.8 & $0.6-4.9$ & .27 & .42 \\
\hline & Verbal & 1.0 & $0.6-1.7$ & .86 & 1.1 & $0.5-2.5$ & .73 & .72 \\
\hline Dating violence & Yes & 1.5 & $0.7-3.0$ & .28 & 4.0 & $0.9-18.1$ & .08 & .41 \\
\hline \multirow[t]{3}{*}{ Family adversity } & Deceased parents & --- & ---- & --- & 4.6 & $1.2-17.7$ & .03 & .54 \\
\hline & Parental psychopathology & 1.1 & $0.6-1.8$ & .79 & 2.4 & $1.1-5.1$ & .03 & .40 \\
\hline & Violence between parents & 3.5 & $1.7-7.2$ & $<.01$ & 0.3 & $0.1-0.9$ & .03 & $<.01$ \\
\hline \multicolumn{9}{|c|}{ RECENT STRESSFUL EXPERIENCES (12-MONTH) } \\
\hline & $\begin{array}{l}\text { Life-threatening illness or } \\
\text { injury of a friend or family } \\
\text { member }\end{array}$ & --- & ---- & --- & 0.5 & $0.3-1.0$ & .04 & .35 \\
\hline & $\begin{array}{l}\text { Stressors related to } \\
\text { romantic partner (break-up } \\
\text { or cheated) }\end{array}$ & --- & ---- & --- & 2.0 & $1.0-4.0$ & .05 & .13 \\
\hline & $\begin{array}{l}\text { Betrayal, arguments or } \\
\text { break up with friends or } \\
\text { family member }\end{array}$ & 1.2 & $0.7-2.0$ & .49 & 1.2 & $0.6-2.5$ & .57 & .68 \\
\hline & Interpersonal conflicts & 1.6 & $0.8-3.2$ & .20 & 1.3 & $0.6-2.8$ & .49 & .95 \\
\hline & $\begin{array}{l}\text { Seriously physically } \\
\text { assaulted }\end{array}$ & --- & ---- & --- & 1.4 & $0.5-3.8$ & .57 & .85 \\
\hline & $\begin{array}{l}\text { Trouble with the police or } \\
\text { serious legal problems }\end{array}$ & --- & ---- & --- & 1.9 & $0.8-4.7$ & .17 & .21 \\
\hline & Other stressful experience & 0.7 & $0.3-2.0$ & .55 & 0.4 & $0.1-1.7$ & .23 & .16 \\
\hline \multicolumn{9}{|l|}{ INDIVIDUAL } \\
\hline \multirow[t]{3}{*}{ Mental disorders ${ }^{\dagger \ddagger}$} & Mood disorder & 5.5 & $3.3-9.3$ & $<.01$ & 4.4 & $2.0-9.7$ & $<.01$ & .13 \\
\hline & Anxiety disorder & 2.7 & $1.6-4.6$ & $<.01$ & 1.0 & $0.4-2.6$ & .94 & $<.01$ \\
\hline & $\begin{array}{l}\text { Alcohol or substance } \\
\text { disorder }\end{array}$ & 2.1 & $1.1-4.3$ & .04 & 0.5 & $0.2-1.6$ & .27 & .51 \\
\hline \multicolumn{9}{|l|}{ Psychological } \\
\hline \multirow{2}{*}{$\begin{array}{l}\text { Hopelessness } \\
\text { (ref = Disagree } \\
\text { strongly/moderate) }\end{array}$} & Agree strongly/moderate & 1.4 & $0.7-2.7$ & .31 & 7.7 & $2.8-21.2$ & $<.01$ & .02 \\
\hline & Neither agree or disagree & 0.9 & $0.5-1.6$ & & 2.9 & $1.2-6.8$ & & \\
\hline $\begin{array}{l}\text { Chronic health } \\
\text { conditions or physical } \\
\text { impairment }{ }^{\dagger}\end{array}$ & Yes & --- & ---- & & 0.3 & $0.1-0.8$ & .02 & .04 \\
\hline \multicolumn{9}{|l|}{ COMMUNITY } \\
\hline Access to means $^{\dagger}$ & Yes & --- & $\begin{array}{ll}--- \\
\end{array}$ & & 1.6 & $0.5-5.3$ & .47 & .48 \\
\hline \multicolumn{9}{|l|}{ Positive Relationships ${ }^{\S}$} \\
\hline \multirow{2}{*}{$\begin{array}{l}\text { Family support } \\
\text { (ref = Low) }\end{array}$} & High & 0.5 & $0.2-0.9$ & $<.01$ & 0.2 & $0.1-1.0$ & $<.01$ & $<.01$ \\
\hline & Middle & 0.4 & $0.2-0.7$ & & 2.1 & $0.9-4.5$ & & \\
\hline
\end{tabular}


Table 3 (continued)

\begin{tabular}{lllllllll}
\hline $\begin{array}{l}\text { Peers/others support } \\
\text { (ref= Low) }\end{array}$ & High & 0.6 & $0.3-1.1$ & $\mathbf{. 0 1}$ & 0.2 & $0.0-1.3$ & .11 & .13 \\
& Middle & 0.4 & $0.2-0.8$ & & 0.5 & $0.2-1.1$ & \\
$\begin{array}{l}\text { School connectedness } \\
\text { (ref = Low) }\end{array}$ & High & 0.8 & $0.4-1.5$ & .46 & 0.7 & $0.2-2.4$ & .39 & .40 \\
& Middle & 0.7 & $0.4-1.2$ & & 0.6 & $0.3-1.2$ & & \\
\hline
\end{tabular}

Adjusted by: Center, academic field, parents' university studies and living at first term; $p$-value $<0.05$ highlighted in bold. *p-value for F-test to evaluate significance of each variable based on multiple imputation. **p-value for F-test of the interactions between gender with each of the assessed factors based on multiple imputation.

$\dagger$ Reference category: no.

\$ Mood includes Major Depression or Bipolar; Anxiety includes Panic Disorder or Generalized Anxiety Disorder; Alcohol or substance includes abuse or dependence.

$\S$ Family support lowest tertile [1-3.75], middle tertile [4-4.5], highest tertile [4.75-5]. Peers/others support lowest tertile [12.75], middle tertile [3-3.5], highest tertile [3.75-5]. School connectedness lowest tertile [1.17-3.33], middle tertile [3.5-4.17], highest tertile [4.33-5]. 
Table 4. Summary of common and gender-specific risk and protective factors of suicidal ideation among Spanish university students. The UNIVERSAL (University and Mental Health) project.

FEMALE MALE

NEGATIVE LIFE EVENTS AND FAMILY ADVERSITY

Childhood maltreatment

Physical

Dating violence

Yes

Deceased parents

Family adversity

Parental psychopathology

Violence between parents

NS

$++$

NS

$++$

INDIVIDUAL

Mental disorders ${ }^{\dagger}$

Mood disorder

Anxiety disorder

Alcohol or substance disorder

NS

$++$

$++$

NS

Psychological

Hopelessness (ref=Disagree strongly/moderate)

Agree strongly/moderate

$+++$

$++$

$++$

NS

$++$

NS

\section{COMMUNITY}

Positive Relationships

Family support (ref=low)

High, Middle

NS

Peers/others support (ref=low)

Middle

NS

Based on logistic model results of the magnitude of the ORs: $+>1$ to $<2,++\geq 2$ to $<5,+++\geq 5$; $* *<1$. NS no statistically significant.

$\uparrow$ Mood includes Major Depression or Bipolar; Anxiety includes Panic Disorder or Generalized Anxiety Disorder; Alcohol or substance includes abuse or dependence. 
Figure 1. Flow diagram of the number of individuals at each participation stage. The UNIVERSAL (University and Mental Health) project.

\section{Inclusion criteria:}

Age 18 to 24 years

Enrolled in the $1^{\text {st }}$ year of University for

the first time

Exclusion criteria:

Not accept inform consent

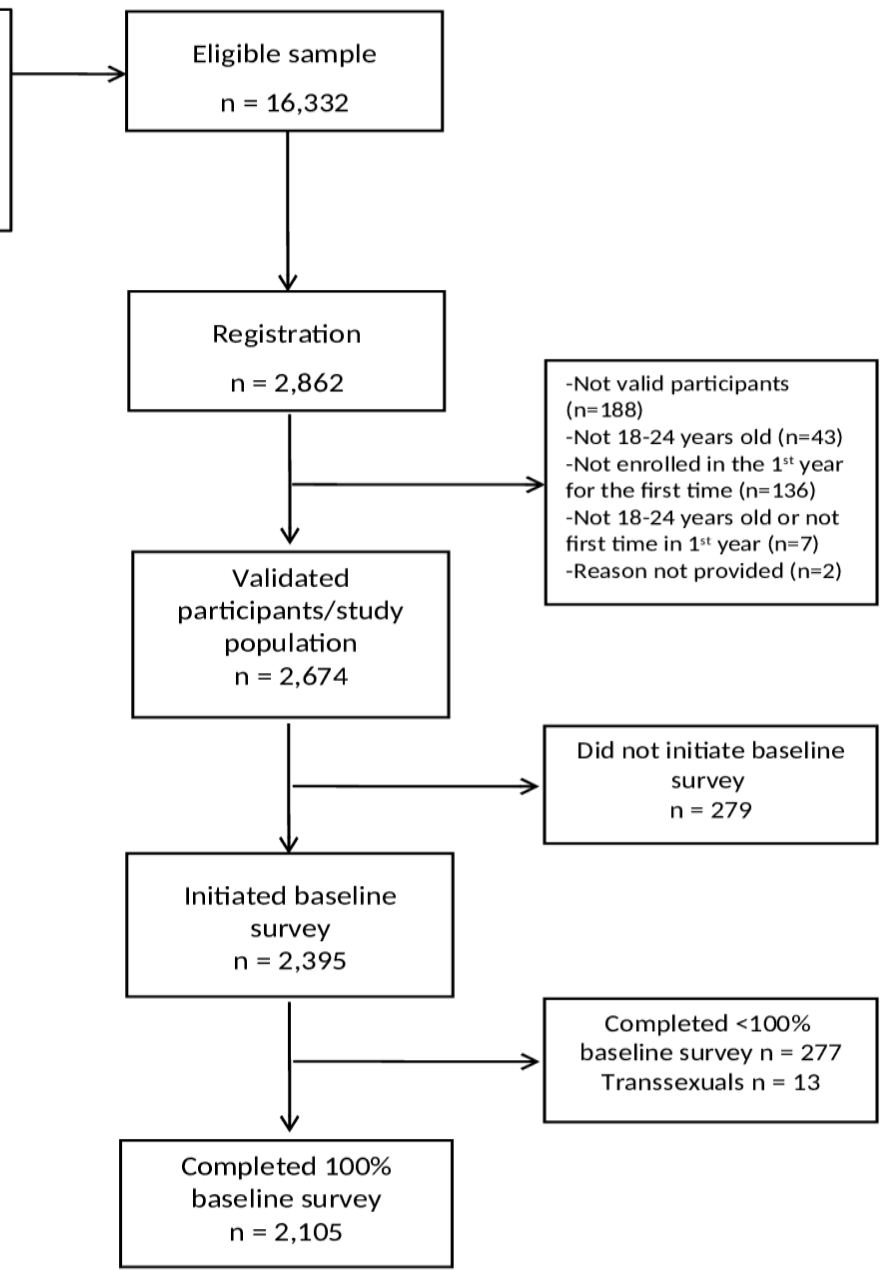

